\title{
Polymerase chain reaction detection of Pasteurella multocida type B:2 in mice following oral inoculation
}

\begin{abstract}
Haemorrhagic Septicaemia (HS) is an acute, fatal, septicaemic disease of cattle and water buffaloes caused by Pasteurella multocida, serotype B:2 in tropical countries. The limitations associated with accurate predictions of mortality, survival levels and the detection of the presence of the organism from various organs of infected animals. Hence, this study used mouse model to evaluate the pattern of mortality and bacterial recovery from organs. Twentyfour mice were randomly divided into two groups. Infected group were inoculated orally with 109 colony forming unit of $\mathrm{P}$. multocida type B, the group 2 were negative controls. The mice were observed for 5 days post-inoculation. At necropsy, visceral organs of dead animals were subjected for the confirmation using Polymerase Chain Reaction (PCR). The results showed that mortality rate was significantly different $(\mathrm{p}<0.05)$ between the infected and control groups. Within infected group, highly significant difference $(\mathrm{p}<0.05)$ was observed where $12.5 \%$ of the mortality rate was recorded within $24 \mathrm{~h}$ and $62.5 \%$ within $48 \mathrm{~h}$ postinfection. The survival rate, in infected group, was found to be around $25 \%$. In diagnosis, $\mathrm{P}$. multocida type B was detected from all organs of animals that did not survive. In contrast, P. multocida type B was neither recovered nor detected from the organs of mice which survived until the end of the experimental period $(120 \mathrm{~h})$. The results of this study indicated that manipulation of the organism in experimental animals provided clear information of the incidence of the disease in the field.
\end{abstract}

Keyword: Pasteurella multocida type B; Oral inoculation; Polymerase chain reaction; Mice; Organs 